\title{
Critique of Academic Proposals that "Chinese Dragon Totem Stemming from Prairie Wolf Totem” in Wolf Totem
}

\author{
Wu Juan", Xue Wenhui \\ School of Foreign Language, Beijing Institute of Technology, China
}

Copyright $(\mathcal{C} 2015$ by authors, all rights reserved. Authors agree that this article remains permanently open access under the terms of the Creative Commons Attribution License 4.0 International License.

\begin{abstract}
In the annexed article of Wolf Totem, academic proposals that "Chinese dragon totem was stemmed from prairie wolf totem and there was a period of taotie totem between dragon totem and wolf totem", gave rise to heated discussion. This paper exams the wolf-totem proposals by textual analysis and archeological evidence to indicate that there was no obvious trace of wolf-worship had been discovered in the Chinese prehistoric culture, there was no recognizable element of wolf had been found in the components of Chinese dragon, and there was no cohesive relation between taotie design and wolf totem. Thus such proposals initiated in Wolf Totem should be taken into reconsideration and conducted with more substantial evidences, otherwise they might affect the ever-growing readers with some misunderstanding or even doubts on the significance of Chinese totem and formation of Chinese culture identity.
\end{abstract}

\section{Keywords Wolf Totem, Dragon Totem, Taotie Design}

\section{Wolf Totem and Its Academic Proposal}

The blockbuster Wolf Totem, based on the original novel, was released in the March this year. With the French director Jean-Jacques' s years of strenuous efforts and the famous singer Wang Feng's soul-stirring song, the craze of wolf worship swept the whole of China and gave rise to heated discussions. Wolf Totem was set in the background of Mongolian Herder's living environment and reflected some aspects of Mongolian people's social life and historical culture. After the novel was publicly published and officially issued, some sort of stir arose in the local Mongolian readers. The translated Mongolian version provided the Mongolian readers with the chance to appreciate this novel in their native language. Wolf Totem became one of the best sellers in the Chinese domestic book market from 2004 to 2005 and kept ranking the top in many major booklist. Discussions about the so-called "wolf spirit", inspired by Wolf Totem, were not only confined to the cultural study, but also extended to the business management. Publishers vied to bring out books of promoting wolf spirit, such as Wisdom of Wolves, Management of Wolf Nature Principle, etc.

Different from common fictional novel, Wolf Totem was published with a lengthy academic appendix, which was entitled as "A Rational Exploration-Lecture and Dialogue on Wolf Totem" (hereinafter referred to as "lecture and dialogue" ). Jiang Rong, the author of Wolf Totem, in the annexed article of the novel, proposed that "the totem of Chinese dragon was derived from prairie wolf totem and there was another period of taotie totem between dragon totem and wolf totem". [1: 407] Besides, he asserted that "the first dragon of China" unearthed by Hongshan cultural relics culture, which was widely-accepted and vigorous-proved as the swan-dragon, should be re-interpreted as a jade article with dragon-head and wolf-body, and it could be called as jade-wolf, or dragon-wolf . [1: 403].

The editor and the executive planner of this novel, An Shunbo, reiterated these academic proposals that "wolf is the ancestral beast, antecedent, warrior, and paragon. we glibly claim ourselves to be the descendants of the dragon, but have you ever considered that dragon totem probably derives from nomadic people's wolf totem. Will the dragon worship be unveiled unprecedentedly ever since? Are we on earth the descendants of dragon or wolf ?" [1: 1-2] and entitled the novel with a controversial and stunning recommended statement "Are we the descendants of dragon or wolf?" [1: 1] Such proposals drew readers' attention to the Chinese multiethnic cultural resources, yet they were deduced without rigorous academic research and lack of substantial textual and archeological evidence, which might affect its ever-growing readers with some misunderstanding or even doubts on the Chinese cultural history of nationalities. Thus, it was necessary and imperative to analyze these proposals with an aid of reliable textual and material evidences to clarify the connection between totems of wolf, dragon and taotie, and the formation of Chinese civilization.

\section{Critical Review of Academic Proposals in Wolf Totem}


With regard to the academic proposals in Wolf Totem, there were some critical review articles queried the hypothesis of wolf-totem. Among them, Ye Shuxian, the head of Chinese literary-anthropology association, said that Wolf Totem was far more than an imaginary fiction, actually it spontaneously functioned as a significantly academic expounder, "The penname, Jiang Rong took for himself, was highly suggestive. The novel-planner, An Boshun adopted a sensational title, 'Are we the descendants of dragon or wolf?' Obviously, this novel transformed from a piece of literary creation to a kind of specialized cultural archeology. General readers without rigorous research were unable to judge the fact from fiction. Whether was the worship of wolf prevalent in the ancestral age?" [2: 73] Ye not only showed his disagreement on the academic proposals in Wolf Totem, but also warned that, with the sale of the copyright of this novel's English version, the film rights were sold for a high price of one million dollars, we should take the academic proposals in Wolf Totem seriously so as to avoid misperception brought about by the novel. [2: 76] In Bear Totem-A Probe into the Original Mythology of Chinese Ancestors, Ye carried out a cultural comparison and anthropological exploration by putting the bear-dragon, unearthed in northeast china, at the background of Eurasia bear's mythology and reached a point that "bear are prehistoric totem of china and dragon totem derives from bear totem" [3: 208].

Besides, some Mongolian scholars also made their comments on the academic views in Wolf Totem. The author of Wolf Totem defined the binary opposition of nomads and farming tribe in a rigid and dogmatic manner and asserted that the vitality of farming tribe's sheep characteristics of central plain completely depended on the infusion of wolf characteristics of northern nomads. Su Luge criticize the over-generalized view of wolf-totem in the "On the wolf totem and the blood of Jie people" [4] and "More on the Totem Worship of Mongolian and Turks---- a discussion with Na Mujila" [5]. Su mentioned that Wolf Totem exalted the superiority of western wolf-worship ideology, "the western, small in population and near the ocean, abound with pastures but less reliance on agriculture. Hunting, herding, agriculture, business, trade and seafaring develop hand in hand; prairie wolf, timber wolf, alpine wolf, land wolf, sea wolf have been living freely. The tough and aggressive nature survived tenaciously and strengthened continuously through years of commercial war, trade war and especially in the fierce competition of modern industry. Thus, the tough and aggressive nature in western nations had never been weakened, but increasingly strengthened. A national way of existence determined the given national characteristics, which subsequently determined the national destiny. These characteristics were the important reasons why the western countries caught up and rushed to the forefront of world." [4: 11] Su hold that the author of Wolf Totem took the western superiority as the theoretical foundation and made a farfetched analogy and inferred an uncanny conclusion: "there are two dominant reasons for Mongolia to conquer
Europe and Asia with mere hundreds of thousands of cavalry: The initial reason lied in that Mongolian people were the most devout nomad believing in wolf totem and regarded wolves as the totem of Mongolia, ancestral beast, warrior, antecedent, and paragon and the protector of prairie and prairie people." [4: 12]

Su's critique on the wolf-totem and western superiority might deserve further discussion, nevertheless he put forward a pertinent point that "Interrelation between multi-nationality was a complicated issue that covered a wide scope of subjects, which should not be over-simplified to the binary opposition of farming culture and nomadic culture. We should not overestimate the general features, while ignoring the specific individuality, nor replace specific and detailed analysis with general definition and superficial arguments." [4: 12] Almost every nationality had the complicated mixture of the so-called wolf and sheep characteristics, which could not be over-generalized with simple labels of "wolf character" and "sheep character". History witnessed the interaction between different civilizations in the manner of either war confrontation, or peaceful engagement, which eventually facilitated the progress and development of both civilizations. The Chinese central plain civilization exerted tremendous and immeasurable impacts on its surrounding nations or countries. The multi-ethnic cultural communication was by no means a one-dimensional direction, but a complicated mutual and bilateral interaction. Thus, there are some self-contradiction and immature viewpoints in the annexed article of the Wolf Totem, which had been reflected more or less in academic discussion but still needed more profound analysis. The following part would focus mainly on two specific academic notions that "Chinese dragon totem was stemmed from prairie wolf totem" and "there was another period of taotie totem between dragon totem and wolf totem" to eliminate readers' misunderstandings on the issue.

\section{Criticism of Chinese Dragon Totem Stemming from Prairie Wolf Totem}

\section{i. Cultural Materials of Wolf Worship}

The extrapolation that "Chinese dragon totem was stemmed from prairie wolf totem" proposed in Wolf Totem was difficult to set up because there was no obvious trace or explanatory materials about wolf worship was found in Chinese prehistoric cultural materials of artifacts, paintings, sculptures and other plastic arts. If there existed the culture of wolf worship or wolf totem among the primitive people, some traces should be left on some ritual vessels related to primitive religion. However, the ancient relics with wolf decorative patterns, had still not been found.

So far, most of the materials about our multi-ethnics' worship of wolf ancestor or wolf totem and their mythical legends which had been found were related to ancestors of northern Altaic family and few materials showed their 
relation with Chinese ancestors. Besides, nearly all of literal materials about wolves that recorded in ancient Chinese literatures, except names of geographies and weapons, described wolf in a debased or abused manner. For example, "Lang Tun" (wolf devour) (Huankuan in Han Dynasy: Baoxian (eulogize persons of virtue and ideals), Discourses on Salt and Iron (The nineteenth part in volume four of Discourses on Salt and Iron, and a political essays written by Huan Kuan of Runan, the West Han Dynasty, based on the record of Yantie Conference), described a person devouring fiercely and urgently; "Tan Lang"(greedy wolf) (Biographies of Diviners, Records of Grand Historian), was a metaphor for evil persons with insatiable greed; "Lang Ji" (wolf chaos) (Biographies of Jesters, Records of Grand Historian), indicated scattered and untidy chaos. House of Wei in Records of Grand Historian recorded that, "Qin Dynasty with the heart of wolves and tigers was as barbarous as Rong Zhai (also called Rong Di, in ancient time, Chinese people called northwestern minorities Rongzhai), which implied greedy, violent, chasing profit for its own sake, perfidious and ignoring the etiquette and moral conduct [6: 307].

In historical records, the heart of wolves and tigers was called "lang li" (ungrateful wolf) (Strategies of Yan in Strategies of the Warring States ) which compared the nature of wolves to a persons' greed, violence and cruelty; "a heart of wolves" (Biographies of Seven Emperors during the Reign of Dao Wu. Book of Wei and Biography of Huan Xuan from Island of Barbarians: Book of Wei ), meant a greedy and vicious heart; "lang zi ye xin" (ambitious and evil wolf) (Zuozhuan (Commentary on Spring and autumn annals by Zuo Qiuming) ), indicated wolf cubs were hard to be tamed, which was a metaphor for a greedy and violent people with sinister intentions. "lang dang" (corrupted wolf) (Su Shi in Song Dynasty: Calligraphic Rubbings in the West Mansion: A Letter to Introduce the Strict Person Ziming ), indicated frivolous and corrupted; "lang ji" (wolf disorder) (Biography of Chun Yukun, Records of Grand Historian ) indicated scattered and untidy. "Lang Kang" (wolf fight) (New Accounts of Old Episodes) implied arrogant and violent. "lang bei wei jian" (wolf conspiracy) (Duan Chengshi in Tang dynasty: Youyang Zazu (Miscellaneous Morsels from Youyang), generally referred to those people who colluded with each other to perpetrate outrages. In ancient Chinese classics, such examples were ubiquitous and countless.

Certainly, there were some literary cases recorded in the historical book illustrated occasionally that wolf was taken by some Chinese tribes as a symbol of goodness. Liu Yuqing cited these examples from Book of Rites, the Book of Songs, Imperial Readings of the Taiping Era and other documents in his article "Myths of Wolf Ancestor in Northern Peoples of Ancient China and the Wolf Imagery in Chinese Literature" [7: 12]. Besides, some tribes in later Chinese nation inherited the custom of the worship for white wolf. Zhushuji'nian (The Bamboo Annals, history of Wei state in the Warring States Period) said: In the year of Shang Dynasty "a god leading a white wolf with a crook in its mouth entered the temple of
Shang Dynasty". Guo Pu in Eulogistic Picture of Classic of Mountains and Seas said: auspicious white wolf appeared only in the era of the benevolent monarchs. When there was a change of dynasty, White Wolf would appear with holding a hook in its mouth. White wolf appeared only in the palace of the benevolent monarchs, so it appeared in Shang Dynasty which replaced Yin Dynasty." The volume ninety-nine of Yiwenleiju (A classificatory compilation of literary writings) cited from Duanyingtu also said: "only those who are benevolent, virtuous and wise monarch can see the white wolf". In some cases white wolves also provided help to people in adversities. The Book of Song, The Book of Wei and other historical books also recorded some white wolves' deeds of goodness.

It was worth noticing that the positive images of wolf recorded above were boldness, power, or image of holiness and goodness. Even if these records indicated that there existed a cultural phenomenon of worshiping white wolves in some part of the China wolf was not revered as ancestral beast and totem like what was described in the myths and legends of northern Altaic tribe. In northern nations, the worship of white wolves enjoyed popularity and was unfailing. Guoyu (Chronicles of the spring and autumn) said: Emperor Mu of the Zhou Dynasty subjugate Quan Rong( a barbarian tribe to the west in ancient China), and "returns with four white wolves and white deer" [8: 3]. Annals of Zhou Emperor, volume four of Records of Grand Historian, recorded a chronicle about the King Wen of the Zhou Dynasty subjugating Quan Rong. Emperor Mu of the Zhou Dynasty crusaded against Quan Rong and conquered the nation. Obviously, the so-called "four white wolves and four white deer" were not wolves and deer in the natural world. It referred to those tribes in Quan Rong who treated white wolf and deer as the totem and were named after their totem. Perhaps influenced by northern Altaic peoples, some tribes in ancient China acquired a particular worship for white wolf. Or rather, some wolf-worship tribes in ancient Central Plains (comprising the middle and lower reaches of the Yellow River of China) migrated into central mainland of China from north of the Great Wall.

\section{ii. Literal Evidence of Bear Totem}

It was generally accepted by academia that Yellow Emperor, the earliest cultural ancestor of China, revered bear as the totem of his tribe. Ye Shuxian, in Bear Totem-A Probe into the Origin of Chinese Ancestors' Myth, applied multidisciplinary and multi-evidence to prove his proposal that the ancestral totem of China was the divine bear. Most mythologies about wars of Yellow emperor described the totem of Chinese ancestors as bear or brown bear and other ferocious animals. Five Emperors' Integrity (the sixty-second part of Da Dai Rites which complimented the ability and integrity of Five Emperors and recorded the dialogue between Zai Wo and Confucius when Zai Wo asked Confucius about Five Emperors), in which Da Dai Rites said, "Yellow Emperor trained bear, pi (brown bear), fabulous wild beast and tiger to fight against Chi Emperor in the field 
of Ban Quan, after fighting three times, he achieved his great success." Annals of the five emperors of the Records of Grand Historian: "Yan emperor planned to intrude and bull vassals and all vassals surrendered and submitted to Xuan Yuan Emperor. Xuan Yuan trained bear, pi (brown bear), pi(a mythical bear like wild animal), xiu (auspicious beast) and tiger to fight against Yan Emperor in the field of Ban Quan and after fighting three times, he realizes his ambition." [9: 1] Yellow Emperor in The Book of Lieh Tzu (A book written in the Warring States Period by Liezi of the Zheng State, which contained stories and fables to elucidate the Taoist philosophy of cooperating with nature): "Yellow Emperor fight Yan Emperor in the field of Ban Quan with bear, pi (brown bear), wolf, leopard and tiger as the spearhead and eagle, he (brown long-tailed pheasant), hawk, and glede as the flag." Historical books also recorded the war between Yellow Emperor and Chi You (a mythological warrior engaged in fighting with the Yellow Emperor and the tribal chieftains of Jiuli tribe in the early ancient China). In the war, troops led by Yellow Emperor were symbolized by animals' image as well. In Records of the Following History of Lushi (a book in Song Dynasty recorded historical events and legends about histories, geographies, customs and tribes, etc.), Luo Zhu quoted from Long (dragon) Yu (fish) He (river) Tu (picture): "In the early stage before Yellow Emperor ruled, there was a person named Chi You with seventy-two tribal confederations". In Zhushuji'nian (The Bamboo Annals), Shen Zhu stated: "Tribes belonging to Chi You were bear Tribe, Pi (brown bear) Tribe, Tiger Tribe, Leopard Tribe." Both Yellow Emperor and Chi You had tribes who used animal image as their symbol. Generally, these animals were considered as the totems of tribes respectively. Their clans or tribes were named after the animal, including ferocious quadruped animals like bear, pi (brown bear), pi

(a mythical bear like wild animal), xiu (auspicious beast) and leopard and wolf appeared just once. Therefore, there was a small probability that ancient Chinese ancestors revered wolf as their ancestral beast or totem.

In House of Zhao of Records of Grand History, Sima Qian recorded that, bear and pi (brown bear) were two ancestral beasts of Jin state. (Sima Qian, 1972: 1786-1788) In other words, Jin people regarded bear and pi (brown bear) as their totem. According to the study of Wei Juxian, ancestral beast of Fan Clan(a powerful clan of the Jin state during the Spring and Autumn Period in ancient China) was bear and Zhong Hang clan (one of the six patriarchal clans of Jin state in the period of Eastern Zhou Dynasy) 's ancestral beast was pi (brown bear). Thus the scope of states which regarded ferocious animals like bear and pi (brown bear) as their ancestors of totem was expanded from the three states of Qin, Zhao and Chu to Jin state. [3: 175] Therefore, many tribes of ancient Chinese ancestors near northern region regarded bear, pi (brown bear) and ferocious animals as their totem and few of them took wolf as their totem or ancestral beast. Those who took wolf as their totem were mainly confined to Northern Altaic Turkic tribes, Mongolia and other ancestral tribes. The possible reason why the cultural tradition and primitive language between Central China and Northern Altaic tribes were vastly different was that ancestors of these two consanguinity tribes survived and developed independently in different regional environment. The convergence and assimilation of Northern Altaic tribes and Chinese ancestral people were evolved by years of cultural contact, merging and accumulation during the prolonged process of Chinese historical development. The pattern of Chinese pluralistic unity, a remarkable assertion put forward by Fei Xiaotong, can be applied to this phenomenon. Thus pluralistic relation between Northern Altaic tribes and Chinese ancestral people could be traced back to pre-historical stages of worshipping for ancestral beast or totem.

\section{iii. Archetypal Components of Dragon Totem}

The totem worship was closely related to a special stage of human history-Clan system in which heterogeneous cultural traditions and tribes with complicated affiliation were merged into a stable human community-it was impossible for the different ethnics to acquire a unified totem worship. In China, dragon enjoyed a traditional priority among apocalyptic animals. The attributing divinity of dragon entitled dragon a further distinction of occupying a central canonical position or bearing a heavier weight of conceptual meaning. The archetype of "Chinese Dragon" was supposed to be animals like snake or python which indicated that ancient Chinese people took snake, python or other similar animals as their totem. Image evidences of the prehistoric times recorded the coition between Fuxi and Nuwa, Chinese earliest ancestors as an image of human-body and snake-tail, which proved the fact that Chinese ancestors once worshipped snake totem. As the evolution of Chinese dragon, some scholars explained that: "ancient snake-worship clans and tribes constantly conquered and amalgamated other tribes, which contributed to the constant mergence of snake totem with other totems, therefore the totem changed and evolved gradually. When the basic image of Chinese dragon was formed, new cultures from the barbarian tribes in the east and north of ancient China intervened into central mainland and were merged with the system of dragon culture, which finally formed the image of modern dragon which carved into the Huabiao columns." [11: 11-12] However, the evolutionary process ofdragon image was the declining process of the totem's deity. Ironically, when its basic image was formed eventually, its function as the totem no longer existed any more. It became a kind of mascot or symbol which subtly revealed prototypical information and it carried and revealed the mysterious message of ancient totem which was almost inaccessible to the modern people.

The image of Chinese dragon was evolved gradually through a prolonged process. The dragon on bronze-ware of the Shang dynasty was a groveling monster with snake body and beast head. However, after going through the national integration from Warring States to Tang dynasty, Dragon changed into ox's head, pig's snout, horse's mane, antler, 
goat's beard, snake's body, fish's scale, eagle's claw and became a blending image owing to the mergence of diverse animal totems. It is worth noticing that another main totem of grasslands nationality - deer, whose antler erected high above the dragon head revealing a powerful and unbending looking. During Qin and Han Dynasty, it was ox horn that erected above the dragon head. After going through $\mathrm{Wu} \mathrm{Hu}$ uprising (a historic event that northern five minorities march south extensively and intrude Central Plains which happened in the Northern and Southern Dynasties), "the flourishing Sui and Tang dynasties stepped towards unity and ox horn changed into branching antler. The meaning it conveyed was self-evident. However, wolf was abandoned completely." [7: 12] There was no hard evidence could be found to prove that wolf contributed to the evolvement of Chinese dragon, as Liu Yuqing said, "In the traditional Han ethnic group, we could find names or nicknames like tiger, leopard, dragon, Jiao (flood dragon, a mythical creature capable of invoking storms and flood.), eagle, rabbit, mouse, however, in which wolf was hard to be found. Here, It abandoned not just a name but abandoned completely the barbaric primitive lifestyle, the behavior of grappling and plundering and the worship for the spirit of fierce and tough." [7: 12] Though tiger was a cruel and ferocious carnivore which posed a great threat to human life and property, both Northern Altaic tribes and Chinese ancestral people were willing to include it to their culture, because it might be easier for Northern Altaic tribes and Chinese ancestral people to attain and share a similar value-judgment about the imagery of tiger, rather that of wolf.

From above, we could see that many totem fragments could be found in Chinese dragon, yet the imagery of wolf was indeed hard to be found and was rejected by the prehistoric farming ancestors. Thus, it was improper to say that Chinese ancestor's worship for dragon totem derives from northern nomad's worship for wolf totem or that Chinese ancestors originally revered wolf as their totem, which was unconceivable.

\section{Archetypal Analysis of Taotie Design and Wolf Totem}

\section{i. Literal Documents of Taotie Design}

The article "lecture and dialogue", which was annexed to the novel Wolf Totem not only put forward that Chinese dragon totem was stemmed from prairie wolf totem but that "there was another period of taotie (an atrocious and voracious mythical beast) between dragon totem and wolf totem." Taotie design was a kind of patterns of animal's face carved onto the jia (a small jade or bronze wine vessel with ears and three legs) or ding (a large three-leg bronze vessel and the central artifact used in ceremonies, especially sacrifices and court banquets.) Taotie design was plastic art of highly-abstract, geometric-animal mask, which was imagined by ancient Chinese people. Which animal did the archetype derived from? Whether Chinese ancestors took it as the totem animal or not? If in that case, how did primitive people worship it? It is hard to give convincing answers for these questions because of lacking relevan materials. Taotie design was an imagined animal figure, which derived from facial archetypes of various animals. Taotie design was not a plastic art for purely aesthetic significance; rather it combined and merged the characteristics of animals to illustrate an underlying ancient people's faith and belief. Thus, there was no obvious connection between wolf and taotie design. In other words, the archetype of Taotie design could not be derived from wolf.

As the feature of taotie design, some scholars pointed out, "it was difficult to figure out that whether we should use horn and mandible to judge the features of this creature or simply focus on the final effect of changes. Limited features mixed and brought about extensive changes in motif. This kind of mixed feature, especially the horns, might use real animals including buffalo, ram as references." [12: 102] According to some scholar, taotie might be the abstraction of bear, thus "bear was one of the animal archetypes of taotie". [3 102] In addition, some of the decorative patterns of taotie were identical to tiger design. In 1991, the $9^{\text {th }}$ large tomb of the Hou Gang sites in An Yang, a lip of bronze gong (an ancient wine vessel made of horn), which belongs to Shang dynasty, was unearthed. The lip was designed with deer's head as its head and tiger's head as its tail and the both sides of the ridge was decorate with Kui (a mythical snakelike uniped creature) design. The special design of tiger's head in its tail was found to be identical to taotie design, and tigers were associated spontaneously to taotie design. From above, we could see that the taotie design was a highly abstract and geometric decorative design, which derived from various animal facial designs. However, it was hard to determine that it came from a specific category of animal and taotie design exhibited no obvious signs of wolf design.

\section{ii. Historical Records of Taotie Design}

There were many records of taotie design in historic books. Annals of the Five Emperors in the Records of Grand Historian recorded: "Before, Emperor Di Hong had a notorious posterity who blotted justice and humanity, shielded ferocious brutal person and liked breaking the law and committing evils. All people called him Hundun, which meant barbaric and uncivilized. Emperor Shao Hao also had a notorious posterity who destroyed credit, discarded justice, loathed loyalty and righteousness, and liked vicious language. All people called him Qiongqi, which mean wired and bizarre. Emperor Zhuan Xu had a notorious posterity who was uncivilized and had no idea how to distinguish good words from bad words. All people called him Chouwu, which meant ferocious and obstreperous. People were afraid of these three families. Emperor Jin Yun had a notorious posterity who was esurient in eating and greedy in wealth, who was named by people as taotie, which meant ravenous and voracious. He was more furious and violent than the 
above three varlets and was loathed and feared by all people." [9: 4] Spring and Autumn Annals also stated "the man called taotie was the notorious son of Jin Yun." The 18th Year of Duke Wen in Zuozhuan said: "Emperor Jin Yun had a notorious posterity and he was esurient in eating, greedy in wealth. He was indulged in luxury and never felt satisfied. He plundered and accumulated vast wealth illegally, yet showed no sympathy for the orphans, widows and the poor. Thus he was compared by the citizen to the three demons, and was named taotie.

In ancient Chinese, taotie was the byword of voracity and avarice. Binglüe xun in Huainanzi (a collection of various philosophical treatises compiled under the mentorship of Liu An (179-122), Prince of Huainan, during the mid-Former Han period) said: "Those people who were avaricious, outrageous and ferocious did harm to common people and cause people to lead a turbulent life". The ancients used "taotie celestial being" referred to those monks who did not focus on self-cultivate and self-perfection, but admired secular fame and wealth. Song Taogu's Qingyilu Xianzong (a novel that records trivia knowledge and various novel names of people, events and things with their origin in the Han Dynasty) stated: "Celestial beings who were attracted by dusty world did not control their desire, but tried all ways to plunder wealth, therefore were named as Taotie celestial being."

\section{iii. Archeological Evidences of Taotie Design}

Not only taotie was recorded in historic books, its decorative designs were found frequently in Jia or Ding of Shang and Zhou Dynasty. In the northeast area of China, Taotie designs had been found in the Ji'an Koguryo murals. According to the archeological investigation, the taotie design was more vividly curved than that in bronzewares of Xi Zhou Dynasty, but its greedy and tyrannous disposition remained unchanged. According to the Records of Ji'an County's Heritage, five characters were inscribed beside taotie: dan (eat) fu (wealth) bu zhi zu (unsatisfied). Thereinto, the character "fu" (wealth) was understood as "meat" by some scholars who suspected that drawer wrote the wrong character, because "this kind of explanation was too simple and one-sided. In fact, taotie not only ate meat but also plundered wealth. It might be more appropriate to use "fu" (wealth). [13:208] Recently, based on the investigation of the original pictures in 1930s, characters above were "dan fu bu zhi zu (eat unsatisfied)". Thereinto, the character was not "fu" (wealth). Experts checked every entry in Cihai (word-ocean dictionary, an Encyclopedia of the Chinese Language.), but still could not find that character. No matter it was pronounced as "rou" (meat), "fu" (wealth), the five characters conveyed taotie's greedy and insatiable disposition.

Then, why the ancients carved taotie, an evil beasts design, onto zhong (a large hollow object made of metal and shaped like a cup which had a hanging that hit the sides and made a ringing sound to give a signal or attract people's attention) and ding (a large three-leg bronze vessel. the central artifact used in ceremonies, especially sacrifices and court banquets. its use was strictly regulated in the Shang and Western Zhou dynasties.) as a decoration? Was this worship for taotie or were there any other symbolic meanings? The ancients would not worship creature which was deemed greedy and violent. Plants and animals which were revered as totem especially by the primitive people should be highly worshipped and adored by people. Creatures which were loathed, hated, greedy and violent would not become the totem. Thus, it was imperative to figure out that the ancients carved taotie onto zhongding was not due to the taotie-worship, but some symbolic implication of taotie.

Almost all of the decorative designs, with no exception of that of Shang and Zhou Dynasty in ancient China, were adopted the symbolic methodology to draw people's attention. According to historic records, a vine vessel carved with taotie design, called "taotie zun(a kind of wine vessel used in ancient times)", was invented by people of Zhou Dynasty. Xuanhe Bogutu ( an important book edited in the year of Xuanhe and this book records ancient bronze wares from Shang Dynasty to Tang Dynasty and in which both pictures and descriptions are provided) said: there was not any decorative design were curved on the edge and foot of taotie zun. Its three sides were decorated with taotie design with an aim to exhort." In other words, the edge and foot of taotie zun(a kind of wine vessel used in ancient times), a wine vessel of Zhou Dynasty, had no decorative designs but its three sides were decorated with taotie design. The symbolic meaning of the taotie design on "taotie zun" was to exhort people to take taotie as a warning and abstain from voracity and avarice. By analogy, the original meaning of ancient people's carving taotie design onto divine jia and ding was not to worship the insatiably avaricious evil creature, but exhort people to behave themselves, as $\mathrm{Wu}$ Xiaoguang claimed that: "carving hideous and greedy creatures on the bronze ding in the history of China was also an exhortation to our modern people." [13:207] Among the 26 items of ding unearthed in the famous Tomb of Fuhao, 12 items of round ding were decorated with complete taotie design. Some scholars hold the view that, jia and ding's "complete taotie design and additional decorative designs originated from animal faces was obviously connected with the rite which attracted people to drink more wine. This rite might be the centre of the whole religious structure." Besides the decorated ones, there were some unearthed Jia or ding were curved with no decorative design. It seemed that ritual activities did not depend on whether the bronze ware had taotie design or not. Taotie was important but not indispensable. [12:102] It was clear that the complete taotie design on jia or ding was exclusively used to attract people who attend a certain religious rite to drink wine. Thereinto, the symbolic meaning of taotie design was derived from its gluttonous characteristics rather than the revering taotie itself.

Supposing taotie design on jia, ding or other wine vessels aimed to attract guests to drink more wine, what were the symbolic meanings of taotie designs on other ritual vessels? 
It was reported that in the tomb of Fuhao, a "taotie animal face axe" was unearthed, which obviously was not a common adornment, much less a daily necessity. It enjoyed more symbolic significance than practical application. The stone axe was decorated with greedy and violent animal mask design of taotie, so as to exhort common people to behave themselves and abide by the social morality and conventions.

Taotie design was a decorative design which had been extensively used in ding or jia of Shang and Zhou Dynasty. It was a highly abstract animal face model which was originated from diverse animal archetypes rather than a certain animal face. Jiang Rong hold the view that Taotie shared the similar greedy nature of wolf and thus taotie totem should be originated from wolf totem. However, greedy was a common feature to almost all animals, because it was fatal for their survival in the ruthless jungle competition. Like other large carnivores, wolf bear the greedy and ferocious nature which had no particular obvious relation with taotie's voracious nature. Therefore, it was unpersuasive to conclude that taotie design's archetype was wolf. In the historic records, the symbolic implication of taotie design was "voracious and avaricious". Thus, it was carved on the ancient article of Zhong Ding with a purpose to warn people to abstain from voracity and tyranny. Even the taotie design curved on jia or ding was to encourage guests to drink and eat to their hearts' content at the banquet. This implication was still derived from the greedy characteristics of taotie. Overall, taotie became the symbol of avarice and was not taken as a totem for worship. Thus, the view that taotie totem was derived from wolf totem was lack of sufficient evidences and was not so persuasive. Besides, totem was the outcome of primitive people's association that their own clan had a relation of consanguinity with certain living or nonliving things and as a totem. It could not be a highly abstract image like taotie design, much less those various highly abstract mascot created by the contemporary people.

\section{Conclusions}

In ancient time, totem had been gloried to an unprecedented value by the primitive society and the particular mode of valuing, perceiving and believing, was bound up with political beliefs and ideological value and connected significantly with the maintenance and reproduction of social power. Totem was definable not according to whether it was fiction or imaginative, but a special kind of complicated system, because it transformed and intensified peculiarity of some animal. Totem with its specific law, structure and device, which was to be studied in themselves rather than reduced to something else, for it had profound root in deeper structure of belief which was as apparently unshakable.

To summary, there was no obvious traces of wolf-worship had been discovered in the Chinese prehistoric culture, there was no recognizable element of wolf had been found in the components of Chinese dragon, and there was no cause-and-effect relation between taotie design and wolf totem. Thus, the academic proposals in the annexed article to Wolf Totem, that "Chinese dragon totem was stemmed from prairie wolf totem and there was another period of taotie totem between dragon totem and wolf totem", could not been taken as the convincing and persuasive argument in the strict sense, and should be conducted with more substantial evidence. However with its sales constantly hitting new high, the issue of its foreign language version and the popularity of its adopted cultural products, these controversial proposals might affect the ever-growing readers and audiences with some misunderstanding or even doubts on the Chinese totem or even the formation of Chinese cultural identity. Thus, it would be necessary to analyze these proposals to clarify some misunderstanding of Chinese totem and it would be imperative for circles of academic and intellectual to exam the wolf totem seriously so as to avoid misperception brought about by the fiction and to prevent some potential adverse effects from continuing.

\section{REFERENCES}

[1] Jiang Rong. Wolf Totem[M]. The Chang Jiang Literature \& Art Press, 2008.

[2] Ye Shuxian. Wolf Totem or Bear Totem--Analysis and Reflection on the Chinese Ancestral Totem[J]. China Book Review, 2006 (10): 73-77.

[3] Ye Shuxian. Bear Totem-A Probe into the Origin of Chinese Ancestors' Myth[M]. Shanghai Jinxiu Article Press, 2007.

[4] Su Gelu. On Wolf Totem and Blood of Jie People[J]. Oirat Studies, 2005 (1): 10-17.

[5] Su Gelu. More on the Totem Worship of Mongolian and Turks----A Discussion with Na Musial [J]. Inner Mongolia Social Sciences, 2006 (4): 34-37.

[6] Sima Qian. Volume 54, House of Wei in Records of Grand Historian[M]. Zhonghua Book Company, 2007.

[7] Liu Yuqing. Myths of Wolf Ancestor in Northern Peoples of Ancient China and the Wolf Imagery in Chinese Literature[J]. Studies of Ethnic Literature, 2003 (1): 9-17.

[8] Xue Anqin and Wang Liansheng. Transformation and comments of Guoyu[M]. Jin Lin Literature and History Press, 1991.

[9] Sima Qian. Volume 1, Annals of the five emperors of the Records of Grand Historian[M]. Zhonghua Book Company, 1972.

[10] Sima Qian. Volume 43, House of Zhao of the Records of Grand Historian[M]. Zhonghua Book Company, 1972.

[11] Liu Yuqing. Totemic Myth and the Traditional Life of china[M]. People's Publishing House, 2002.

[12] Rawson, Jessica. Arts and Cultures in Ancient China[M]. translated by Sun Xinfei. Beijing University Press, 2003.

[13] Wu Guangxiao. Ji'an Koguryo murals[M]. Shandong Pictorial Publishing House, 2006. 